\title{
Water, Livelihoods, and Migration in SIDS: Climate Change and Future Prospects for Carriacou, West Indies
}

\author{
Adrian Cashman ${ }^{1, *}$ and David Yawson ${ }^{2}$ \\ 1 AKWATIX Water Resources Management, Ashford Plantation, St John, Barbados \\ 2 Centre for Resource Management and Environmental Studies, University of the West Indies, \\ Cave Hill Campus, Bridgetown, St Michael, Barbados; david.yawson@cavehill.uwi.edu \\ * Correspondence: adrian.c.cashman@gmail.com or adrian.cashman@cavehill.uwi.edu
}

Received: 26 September 2019; Accepted: 30 October 2019; Published: 15 November 2019

\begin{abstract}
Caribbean Small Island Developing States (SIDS) are among the most vulnerable to climate change, which will have a disproportionate impact on local environments and economies. Whilst there is a growing literature on how Caribbean SIDS can adapt to become more resilient, an issue that has received little attention is with regard to migration as an unplanned response. It is recognised that events such as hurricanes and flooding can lead to internal relocation in the short term, but societal responses to droughts through migration have not generally been investigated. This paper seeks to address this by considering the case of the island of Carriacou, part of the state of Grenada. Carriacou, with its small population, limited land area, and local economy historically based on agriculture, has had a high degree of migration. This is in part a response to limited economic opportunities. Environmental stress, manifest through limited water availability, inappropriate land management, and social conditions, is likely to be exacerbated by climate change and variability. Resultant increases in the frequency and intensity of droughts, in the absence of proactive interventions, are likely to result in non-linear migration, both to Grenada itself and beyond.
\end{abstract}

Keywords: water; agriculture; migration; Caribbean SIDS; climate change

\section{Introduction}

Small Island Developing States (SIDS) have been recognised as a distinct and special grouping of developing countries [1]. They share common features such as small size and limited resources and are environmentally and socio-economically vulnerable due to factors such as limited resource base, dependence on fossil fuels, and land degradation [2]. The economies of SIDS are often open and overly dependent on a limited range of economic activities, such as tourism, and lack diversification of production factors, which are compounded by high transportation costs and high per capita costs to deliver public services and infrastructure, particularly when taking into consideration the ability to generate income. Key economic sectors such as tourism and agriculture can be particularly vulnerable to external shocks such as natural disasters and global economic conditions impacting their socio-economic development [3]. The negative impacts often have long-term effects which compound the developmental challenges that they face. Given their vulnerabilities, the path of sustainable development and prosperity for people and environments for SIDS-promoting equitable economic growth, human development, and responding to the landscape of hazards facing them-is likely to be a challenging one.

Starting from the later part of the 20th century, the economies of many of the Caribbean islands have transitioned from being mainly agricultural to being tourism-based economies. The role and 
importance of agriculture has declined significantly whilst retaining an important symbolic role in society. The spike in global food prices in 2007-2008 and again in 2010-2011 renewed interest among governments in the role of agriculture and food production [4]. Yet, it is far from clear as to whether agriculture and food production can increase their economic contribution. Adaptation to a new and emerging reality is not just about technological solutions but is also a social challenge, framed by human, social, and economic capitals; politics and governance; and national-international relations [3]. It is a reality in which the nature of the threats facing SIDS appear to be intensifying, particularly with respect to those related to climate change and climate variability.

With their existing vulnerabilities and exposures, Caribbean SIDS are among the most vulnerable to climate change and climate variability [5], which will have a disproportionate impact on local economies and on the coastal, marine, and terrestrial environments on which their economies depend [2]. The vulnerability of Caribbean SIDS to impacts arising from climate change, sea level rise, and natural and environmental disasters has been explored by the authors of reference [6]. Although the region generally has a high level of risk, the potential impacts will vary between states in the region. Variation will be influenced by factors governing exposure and resilience, e.g., geography, demographics, economic ability to withstand and cope with disasters, and exposure to extreme climatic events.

Governments have responded to the challenges through a variety of mechanisms. Adaptation to climate change has included investment in physical infrastructure improvements, improved governance arrangements, and measures to climate-proof sectors including health care, agriculture and food production, and tourism. However, the ability to introduce adaptation measures has been constrained by underlying vulnerabilities, particularly economic conditions including slow growth and a reliance on external assistance [3]. Weak economic and employment opportunities are nothing new to the Caribbean, and one response has been the long history of outward migration from the region, driven by the push of limited means of making a living and the pull of higher wages and opportunities elsewhere.

The relationship between climate change and variability on one hand, and migration on the other, is complex, unpredictable, and an ongoing debate. This notwithstanding, there has been a burgeoning literature on climate change and migration, climate/environmental refugees, climate conflict and migration, and trying to better understand the drivers of migration. The Intergovernmental Panel on Climate Change (IPCC) Special Report on Global Warming of $1.5^{\circ} \mathrm{C}$ [7] noted that outmigration from communities dependent on agriculture are associated with increases in global temperatures. Due to the inexorable dependence of agriculture on water availability and high sensitivity to changes in temperature, decreased agricultural production is a good conduit for translating water stresses into new patterns of migration in agro-based communities. Although the Caribbean is expected to be one of the regions most affected by climate change, very little has been written about the potential impact of climate change on migration patterns in the region, and much less on the potential of migration as an adaptive response [8,9]. Existing socio-economic conditions in the region are already drivers of outward migration and the proportion of highly skilled migrants is increasing [9], contributing to increasing levels of poverty and loss of human capital, which in turn impacts the ability to cope with financial, environmental, and social stressors [10]. The question that then arises is to what extent might climate change and climate variability have an effect on migration? Examining this question requires an understanding of the intersection of existing socio-economic conditions, drivers of migration, and expected climatic changes. This paper examines the question of migration and climate change by focusing on the island of Carriacou, part of the Tri-island State of Grenada. Whilst research has shown that the drivers of migration are often context-specific, we consider the prospects for Carriacou as a microcosm of the Caribbean in terms of economic and agricultural activities in the face of climate change and the role of policy and governance.

\section{Research Methods}

This work draws on a mixed methods approach that is quantitative and qualitative, blending primary data collection, secondary data sources, and literature analysis. Given the range of influences 
to be considered, the work spans a number of areas of interest-climate change, economic development, livelihoods, migration, water management, and agriculture.

Primary data collection consisted of semi-structured interviews over several visits to Carriacou with a wide range of persons. The repeated visits from 2014 to 2019 allowed for the development of a good knowledge of the island, the way of life, and the development of contacts with people. Interviews with people took place mostly in natural settings, whether people's homes, in the fields, their place of work, or where they socialized. The persons included farmers, civil servants, hoteliers, security guards, fishers, taxi drivers, caretakers, and others. In each case, informed consent to take notes was sought and granted. Ethics approval had been granted by the University of the West Indies-Cave Hill/Barbados Ministry of Health Research Ethics Committee/Internal Review Board. Secondary data involved the collection and analysis of population statistics, some provided by the Central Statistics Office of Grenada, though other sources of information, such as the United Nations Department of Economic and Social Affairs, were also used.

The primary and secondary data collection is complemented by an extensive review of available literature on migration and migration and environmental stress. Whilst there is a growing body of research and knowledge on this subject area, there is very little that is Caribbean-centric, with the exception of a growing interest in the Caribbean diaspora. That said, there is a well-developed body of published work on rainwater harvesting, particularly as it pertains to Carriacou.

Finally, the work has drawn on the findings of research into the potential effects of climate change, particularly on water availability. This work has looked at the changes in surface water yields under contrasting climate change projections, whilst another study has modelled water deficits in the domestic, tourism, and agricultural sectors under different climate change scenarios.

What follows is a synthesis of the information around the subject of interest, the intersection of climate change and environmental stress, agricultural activity, and migration. The rest of the paper focus on the context of the case study (Carriacou and Grenada), migration patterns, and prospects for a fight or a flight under future conditions.

\section{Background/Context}

Grenada, located in the Eastern Caribbean, is the southernmost island of the Leeward Island chain. Grenada consists of the island of Grenada itself plus six smaller islands which lie to the north of the main island. Grenada is also called the "Island of Spice" due to its production of nutmeg and mace, of which it is world's second largest exporter. Carriacou, located to the north of Grenada, see Figures 1 and 2, is the largest island in the Grenadine Islands, being approximately $11 \mathrm{~km}$ long by $3 \mathrm{~km}$ wide and with a land area of $33.7 \mathrm{~km}^{2}$. Geographically, it is characterised by a mountainous spine running the length of the island and a maximum height of $291 \mathrm{~m}$. The name Carriacou is derived from the name the original Carib settlers gave to the island, Kayryouacou, meaning "the land of reefs". Prior to the arrival of Europeans in the Caribbean, the Windward islands were inhabited by the Kalinago (also called Caribs). Little is known of the island prior to a recorded visit to the island by a French explorer in 1656, and no mention is made of meeting islanders during the visit. However, mainland Grenada had by that time been 'pacified' by the French a few years earlier in 1650, when a treaty and cessation of violence was agreed to by the Kalinago chief Kaierouane. What happened to the original inhabitants is not recorded, and the island may have been unsettled in the early $1700 \mathrm{~s}$. However, by the middle of the 1700s, the French had established a plantation-style economy. Slaves to work the plantations were initially brought by the French from Guadeloupe. After the transfer of Grenada and Carriacou to the British in 1783, slaves were imported from Africa, and today, the people of Carriacou affiliate themselves with Africa. In 1776, all plantation estates were surveyed; the island was divided into 50 estates, owned by 49 proprietors, with a population of 86 whites and 3153 slaves. Hill ([11] p. 197) noted, "The culture and social structure of the island is maintained by metropolitan institutions (established by colonial governments) and modified by the folk society. The folk society has its origins in the traditional cultures brought to the island from West Africa, the Congo, Britain, 
and France. The folk society of present-day Carriacou is the result of continuous interplay between the traditional folk culture and the metropolitan culture." The people speak an English dialect as well as standard English.

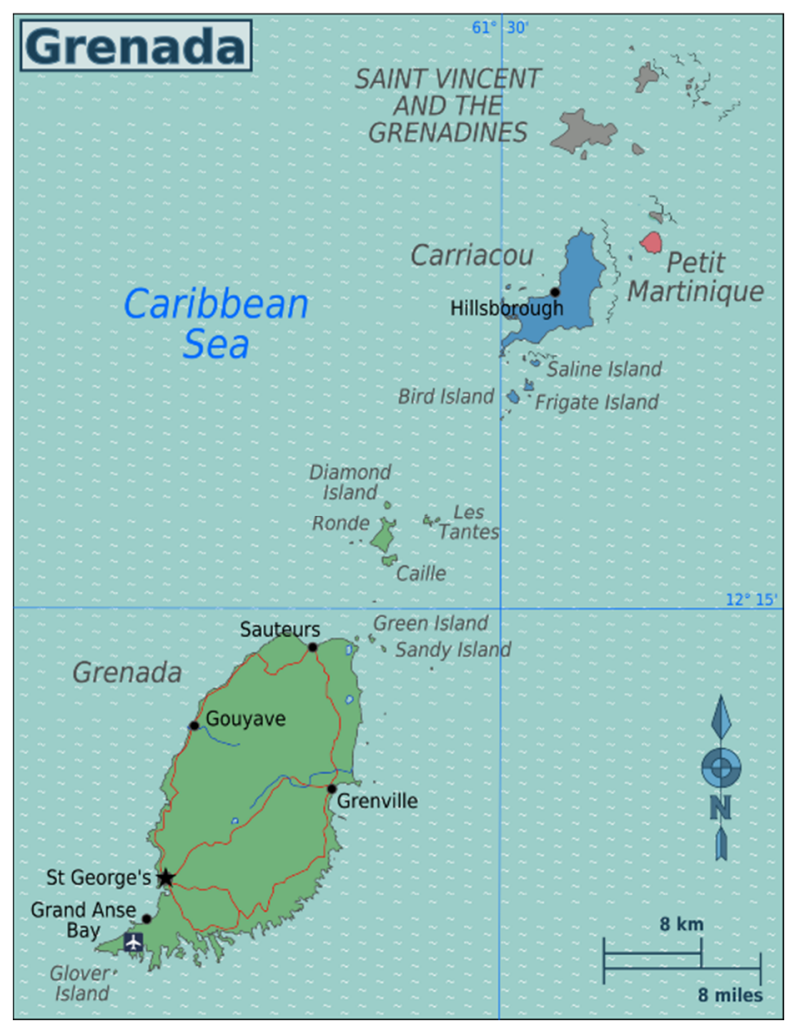

Figure 1. Location map of Grenada and Carriacou.

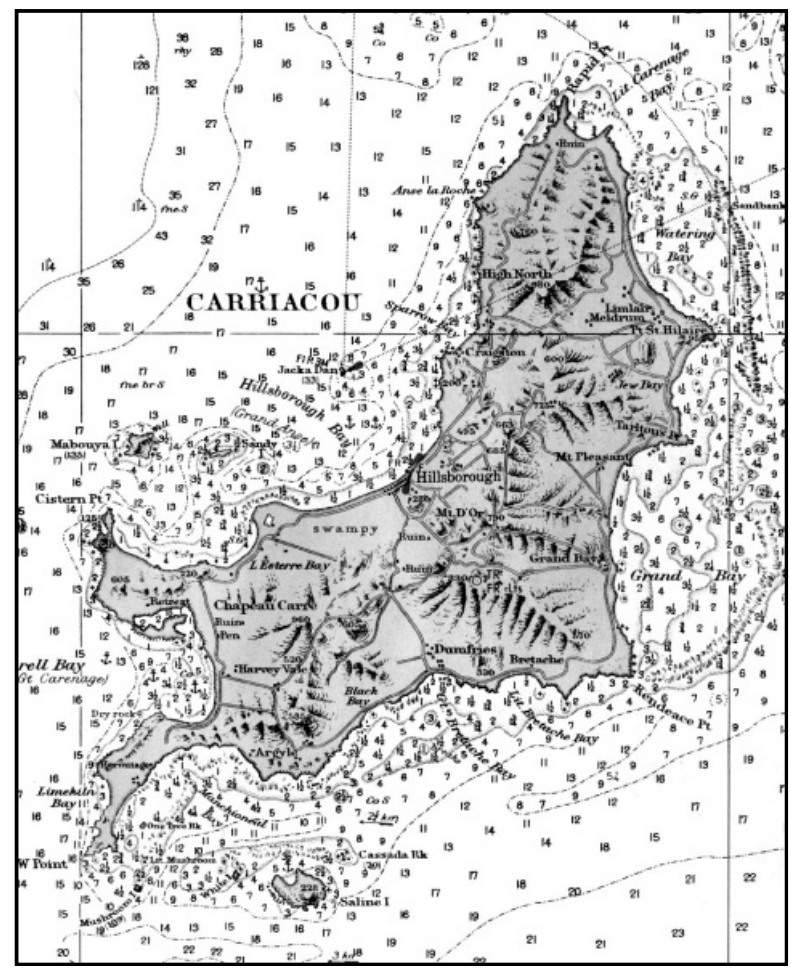

Figure 2. Nautical map of Carriacou, 1891. 


\subsection{Demographics}

In the late 1970s, according to the Grenada's Central Statistics Office in the Ministry of Finance, the population of Grenada was approximately 110,000, but by the mid 1980s, it had dropped to 90,000 and has not fully recovered. According to the 2011 census, the population of Grenada was 105,538, whilst that of Carriacou was 5633 [12]. At the beginning of the 19th century, the recorded population of Carriacou was around 3500 persons, gradually increasing until it peaked at 7100, thereafter showing a gradual but consistent decline [11]. The more recent changes in overall population are shown in Figure 3, whilst the change in population age structure is shown in Figure 4 [12]. The percentage of the population under the age of 20 has declined from $41 \%$ in 2001 to $30 \%$ in 2011 and in absolute terms by 844 persons, whilst the proportion of the population over the age of 60 has increased to $20 \%$ of the population in 2011. Whilst the number of households has shown an upward trend since 1980, the mean household size has declined from 3.8 persons in 1981 to 2.69 in 2011 [12].

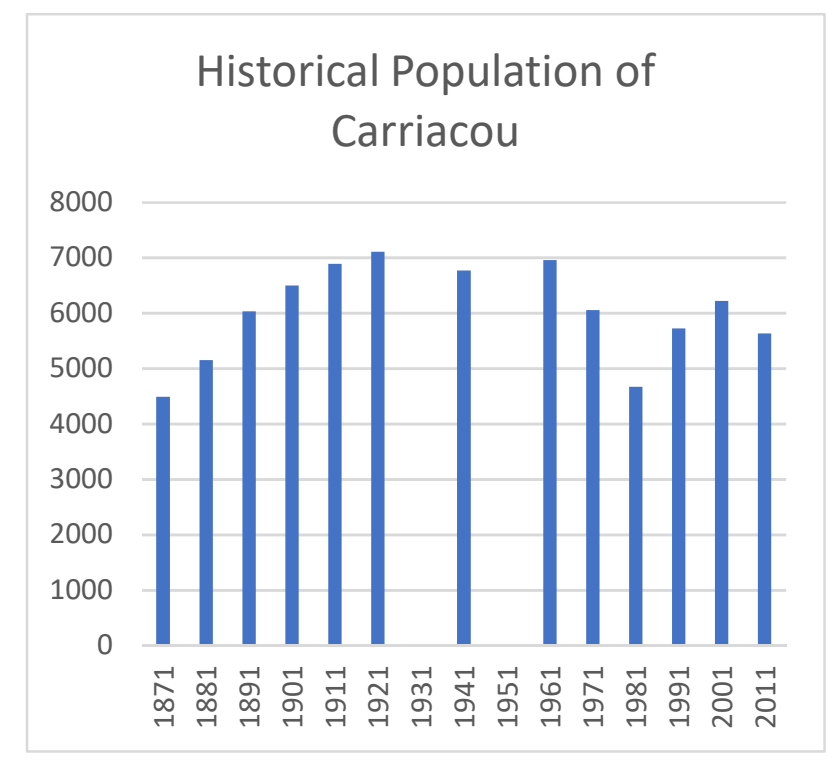

Figure 3. Historic population of Carriacou.

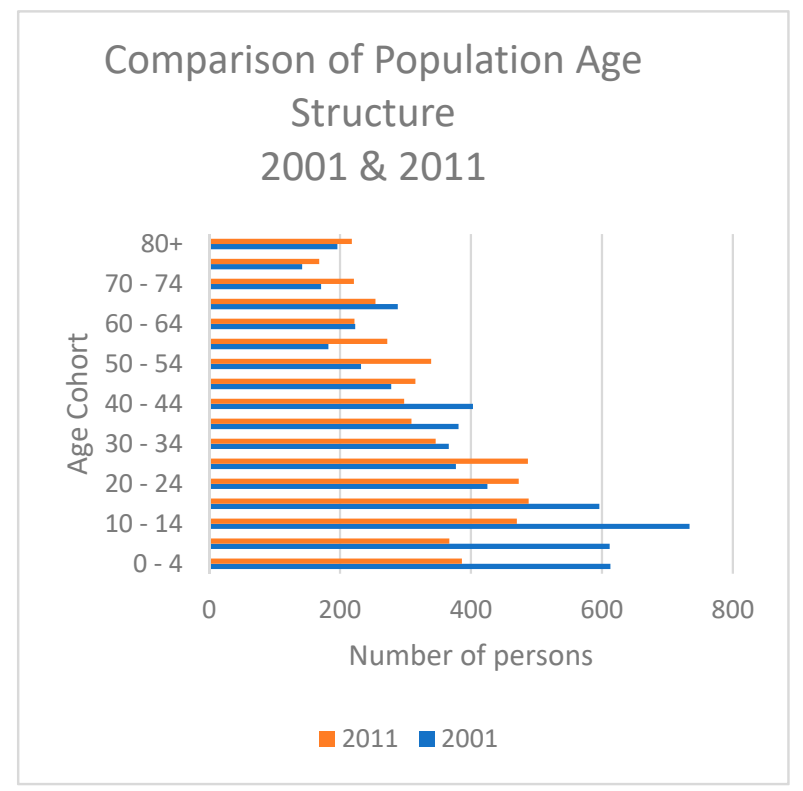

Figure 4. Carriacou's population age pyramid. 


\subsection{Water Supply}

There are no perennial rivers on Carriacou, and although there is some groundwater, it is found in shallow aquifer lenses close to the coastal fringe. In the 1890s, wells were sunk in coastal areas to tap into the shallow aquifers, but the water from the wells is of poor quality, with high quantities of dissolved salts, hardness levels of $300 \mathrm{mg} / \mathrm{L}$ to $500 \mathrm{mg} / \mathrm{L}$, and increasing levels of chlorides. Apart from the development of wells ( 28 in total), there are boreholes (9) that have been developed, but these too are generally of poor quality and low yield. One borehole was used to supply a limited water distribution system in Hillsborough, the main town and administrative centre of Carriacou, but it too has a limited yield of no more than $90 \mathrm{~m}^{3} /$ day.

Historically, the island has relied for its water supply on the capture of rainwater either in ponds and check dams for agricultural use or in communal and household cisterns for domestic use. There are 25 ponds across the island, and these are used primarily for livestock watering, particularly in the dry season. There is no systematic use of ponds to support irrigated agriculture. Communal cisterns can be found at public buildings, schools, hospitals and clinics, churches, community centres, and administrative offices. There are 33 communal catchments and 78 storage facilities for public use [13]. Since the 1970s, there has been a trend toward the installation of household-level roof rainwater harvesting $(\mathrm{RWH})$, and this has meant that the everyday need for communal cisterns has been reduced. As a result, many of the communal and public cisterns, with the exception of those at schools and the hospital, are now either in a poor state of repair or abandoned, although there have been recent efforts to rehabilitate at least three. Every household and building has some form of rainwater harvesting and storage system. Over the past 40 years, an increasing number of households has not only constructed cisterns, but the storage capacity almost tripled. The increase has been facilitated in part by remittances and in part is due to economic growth since the 1980s [13]. The increased availability of water has led to increases in per capita consumption and facilitated the installation of indoor plumbing systems in approximately $80 \%$ of buildings. It has been estimated that the domestic RWH systems installed in Carriacou can meet $66 \%$ of the unconstrained water demand in a normal rainfall year [14]. Estimated water demand is about $800 \mathrm{~m}^{3} /$ day.

In 2015, a solar powered desalination plant was commissioned which can supply $312 \mathrm{~m}^{3} /$ day, and more recently, a storage tank and limited water distribution system for Hillsborough has been constructed. The system has the capacity to meet up to $39 \%$ of the estimated domestic water demand [15]. In addition to supplying a limited number of customers, mainly businesses, through the distribution system, customers can buy water in bulk delivered by tankers to their cisterns. Unfortunately, the desalination system has encountered maintenance and operational problems, and since commissioning, it has seldom been able to provide a consistent supply. There is also reluctance on the part of islanders to utilise this source both on the grounds of willingness to pay and perceived water quality [15].

\subsection{Economic Activity/Livelihoods}

\subsubsection{General}

Following independence in 1974, the country's agriculture continued to be the mainstay of the economy, with exports of bananas and sugar supported by preferential trade agreements and overseas development assistance. By the 1990s, the global economic environment began to change, and preferential trade agreements began to fall away. As a result, the annual rate of economic growth began to decline, and debt began to accumulate. At the same time, the country was transitioning toward a more service-based economy, which was facilitated by the construction of an international airport in 1985. Grenada is now characterised as being a tourism-based open economy, accounting for $15 \%$ of Gross Domestic Product (GDP). In its recent review of economic performance, the Caribbean Development Bank (CDB) noted strong growth has been driven by increased economic activity in construction, tourism, private education, and in manufacturing [16]. 
However, Grenada suffers from high levels of debt, and according to the International Monetary Fund (IMF), it is in 'debt distress', with an external debt to Gross National Income (GNI) ratio of $73 \%$. The impact of Hurricanes Ivan and Emily forced the country to have to refinance infrastructure whilst at the same time continuing to pay off the debts on damaged infrastructure. The global financial crisis adversely affected economic growth and, as a consequence, has limited the fiscal space for development investment, with most public expenditure going to cover recurrent costs rather than capital expenditure. Investment in disaster and climate resilience measures is low [3].

The agricultural sector has been in long-term decline in economic importance, area under cultivation, and numbers of farmers, though agricultural products such as nutmeg, cocoa and other spices account for approximately $47 \%$ of Grenada's total exports [17]. Contributing to this decline in agricultural production was the severe destruction from Hurricanes Ivan and Emily during the 2004 and 2005 growing seasons. Additional challenges include limited food processing infrastructure, which limits value addition, as well as decreasing access to markets by producers [18]. During 2000-2016, the agricultural sector made up $6 \%$ of national GDP and provided employment for $10 \%$ of the working population, the second largest employment source by sector [19], and made a significant contribution to the livelihoods of the rural population. Small-scale farmers ( $\approx 9200$ persons), mainly subsistence, and fishers $(\approx 1500$ persons) make up the largest groups in the food and agriculture sector. However, the sector's growth has been erratic, affected by pest infestation, plant diseases, and weather impacts, as well as structural factors [20].

\subsubsection{Carriacou}

Carriacou's economy is distinct from that of the mainland, reflecting its different historical socio-economic development. The central government, however, does not keep disaggregated data on Carriacou's socio-economic activities. The economy of the island has historically been based on agriculture, though over the last 30 years, a small tourism-based service economy has emerged alongside, construction, and government employment. From the 195's and particularly after independence in 1974 , the role of government agencies increased in importance in providing employment-jobs such as teachers, officers, clerks, policemen, drivers, etc. From the mid-1980s, tourism and tourism-related activities started to provide additional employment opportunities-in hotels, servicing yachts, water taxis, etc.

Before European occupation, the island was originally forested, with deep fertile soils. When the British took over the island in the late 18th century, in addition to the existing growing of cotton, they introduced the cultivation of sugarcane and its accompanying plantation-style export economy. However, the low rainfall was not conducive to a plantation-style economy primarily based on sugar production. Cotton production, another cash crop, also declined substantially. After the abolition of slavery, the growing of sugarcane became increasingly uneconomic, the estates declined, and by 1871, sugar production ceased. Cotton cultivation and processing, which began under French occupation, continued to form an important part of the local economy into the early 1980s, when low prices and labour shortages led to it going out of production. Some estates were turned over to executors, some were occupied by squatters, and it is from around the 1840s that the first wage labour migrations, initially to Grenada and Trinidad, started. It also coincided with dry weather conditions, which reduced the ability to grow subsistence crops and lasted through to the early 1870s [11]. Abandoned land was turned over to the grazing of sheep, pigs, poultry, and cattle, some of which were exported to neighbouring islands. In 1897, a colonial civil servant wrote,

“Then we went on a little further ... and landed at a little decaying island called Carriacou, where all the people were wretchedly poor. It is all owned by a few absentee proprietors in England and the people cannot get land of their own or rent any except by the year at exorbitant terms. I think the experiment of land nationalisation without compensation might very well be inaugurated at Carriacou". (Devas, 1964, pp. 176-177, in [11]) 
In 1870, the growing and processing of limes was introduced as a minor cash crop, which proved to be profitable until it too collapsed in the 1920s in the face of rising competition, and the lime groves were finally abandoned in the 1970s. By 1901, half the land was abandoned and uncultivated, reverting to secondary forest. In 1903, the colonial government initiated the Carriacou Land Settlement Scheme, under which large estates were cut up into agricultural lots as small holdings and 51 building lots for the extension of the main town of Hillsborough (Grenada Handbook and Directory, 1946, in [11]). By 1938, the reallocation of lands was almost complete, and it was reported that,

"Nearly two-thirds of the population are ... peasant agriculturists ... . The total acreage of small holdings is more than double that of estates.... The estates grow limes as their principal crop and cotton and corn are cultivated by tenants on the share system. They employ not more than 400 labourers, and that only for three months a year ... If anything, land settlement has gone too far in Carriacou, with the result that if the peasant's own little holding fails ... he cannot supplement his earnings by estate labour ... ". (Smith, 1962, p. 33, in [11])

However, as a result of deforestation and over 200 years of intensive agricultural practices, much of the land is of poor quality. A CARDI study [21] found that a third was badly eroded, $500 \mathrm{Ha}$ were cultivated, and $750 \mathrm{Ha}$ abandoned formerly cultivated land. Fifty years ago, more of the island was forested and more land was under cultivation than at present. In the 2000s, government land, comprised of former estates, was leased out to a small number of farmers. Erosion, overgrazing, and soil infertility has been noted as a major problem and constraint on agricultural development [21]. Soil erosion is exacerbated by the ripping out of annual crops and burning to control insects, and by the traditional "leggo" season, whereby animals are let loose to graze freely. Carriacou accounts for a third of the livestock population of Grenada, and in the past, livestock was exported to Grenada and even to Trinidad. Over the last decade, there has been a shift, with fewer cattle and more of an emphasis of rearing small stock such as goats, sheep, and pigs. Presently, agricultural activity is overwhelmingly subsistence in nature, where a variety of crops are grown for home consumption. According to the Carriacou Farmers Association, there are approximately 800 registered farmers on Carriacou, but of these, less than 20 are commercial, and only three practice irrigation, having just over $1 \mathrm{Ha}$ each under cultivation. Local production has never been sufficient to meet food requirements; produce is imported from the mainland, and those who used to grow food crops are now turning to the vending of food imports from the mainland, as these cheaper than crops produced locally.

The other major economic stimulus is from remittances. The available data only refers to Grenada as a whole; in 2008, reported remittances amounted to \$64 million USD, or nearly 10\% of GDP [22], this is thought to be an under-estimate. Remittances are mainly derived, in order of contribution, from the United States, Canada, the United Kingdom, and Trinidad and Tobago, reflecting the distribution of the Grenadian diaspora.

\subsection{Climate and Climate Change}

Grenada's climate is tropical, being hot and humid in the dry season from January through to May, and a wet season between June and December, coinciding with the regional hurricane season. Although it is considered to be on the southern edge of the hurricane belt, it has suffered only three major hurricanes in the past 50 years. The mean maximum temperature is $31^{\circ} \mathrm{C}$, the mean minimum is $24^{\circ} \mathrm{C}$, and the mean average rainfall is $1510 \mathrm{~mm}$ [23]. Carriacou generally receives a lower amount of rainfall, between $1088 \mathrm{~mm}$ and $1370 \mathrm{~mm}$ [24], due to a lesser orographic effect and is subject to more severe drought conditions.

Looking to the future, it is projected that mean annual temperatures will increase by between $0.9^{\circ} \mathrm{C}$ and $1.3^{\circ} \mathrm{C}$ by 2050 , but more significant historic trends in mean annual maximum temperatures as recorded at Maurice Bishop International Airport (MBIA) have shown a steady increase since 1985 when records began. This is consistent with climate projections which suggest that the number of days 
when temperatures will exceed $30{ }^{\circ} \mathrm{C}$ will increase. Compared to the $1971-2000$ baseline, up to $50 \%$ of the year is projected to be under warm spell conditions [7].

In terms of rainfall projections indicate a general drying across the Eastern Caribbean, with precipitation decreasing by $20 \%$ during May, June, and July and by $20-30 \%$ between August and December [25]. Although average rainfall is set to decrease, rainfall intensity is projected to increase, particularly in respect of shorter duration events resulting to greater run-off. Recent research into the changes in drought in the Eastern Caribbean indicate that droughts are set to become a more frequent occurrence and that they will last longer than is presently the case [26], and the region is likely to experience moderate to severe drought approximately $26 \%$ of the time [27]. Significant drought periods have been experienced across the Eastern Caribbean between the mid 1930s-1940s, mid 1960s-1970s and more recently in 2000-2001, 2009-2010, and 2015-2016. These years, generally, coincided with population dips in Carriacou, mainly due to out-migration.

The recent IPCC Special Report [7] noted global warming poses a risk to people in SIDS vulnerable to poverty and exposes them to experiencing food and water insecurity, adverse health impacts, and economic losses. Changes in water availability may adversely affect economies and freshwater stress is expected to occur as a result of projected increase in aridity. This is of particular concern since, in summary, for Grenada and the Eastern Caribbean, climate change is expected to increase the number of extreme hurricanes, increase heat stress and the number of hot days, decrease total rainfall, increase rainfall intensity, and increase the occurrence of droughts. All of these would have cascading effects through socio-economic sectors and their responses.

\section{Migration and Climate Change}

The study of linkages between climate change and migration constitutes on-going research [28-32]. The relationship between migration and environment usually starts with linkages between population processes and environmental change, often with an emphasis on migration caused by environmental change. Some researchers have sought to link environmental change as impacting the carrying capacity of the environment, echoing Malthus, suggesting that human activities reduce carrying capacity [33,34]. Migration is one response. Households and communities are not just vulnerable to environmental changes and climate variability, but these changes are increasingly affected by feedback from human activities on them, where each operates in relation to the other [34,35].

A review of available literature indicates that most 'environmentally induced' migration occurs within national boundaries and that trans-national migration is not as common. Four types of environmental migration have been suggested; migration induced by environmental disasters which can result in sudden flows of people, environmental degradation characterised by slower responses over a longer period of time, climate change creates changes in existing environmental conditions and may be seen as an additional stressor of the first two, and forced migration associated with large-scale projects [36]. Hugo [36] goes on to note that the root of much environmental degradation can be traced back to historical processes such as colonial exploitation and the imposition of particular modes of production, the consequences of which are still being felt [37]. At the same time, patterns of land use and livelihoods have also been shaped by international inequalities that govern access to resources and terms of trade.

Where severe environmental degradation occurs, there are three possible responses; stay put and adapt, stay do nothing and accept the situation, or leave [38]. The choice depends on the interplay of a range of environmental and socio-economic factors. Available evidence suggests that migration induced by rapid onset events is short-distance and temporary in nature. Post-disaster interventions are aimed at restoration and greater resilience, e.g., Dominica's "Build Back Better" after Hurricane Maria in 2017. In the interim, households may choose to send migrants as part of an investment strategy [39]. However, continued exposure may motivate people to move on a more permanent basis [28]. In the case of slow onset events such as droughts, the evidence with respect to impact on migration patterns is mixed and depends to an extent on these periodic events or part of a longer-term 
pattern of environmental degradation. In some cases, there have been short-distance moves to where alternatives or more favourable conditions exist, either to continue with existing agricultural practices or to move to urban areas to supplement incomes, predicated on having the necessary resources and opportunities to take advantage of alternative sources of income [28]. Tacoli [40] has suggested that, particularly among communities relying on rain-fed agriculture, short-distance or circular migration to urban areas as a means of income diversification will become increasingly common and important as an adaptation to slow onset events in the face of environmental degradation. However, long-term processes of environmental degradation affect greater numbers than fast onset events and does lead to outward migration, either to urban areas or beyond national borders [39].

Under these circumstances, migration becomes a logical response to environmental deterioration affecting livelihoods and social welfare at the household and community level. It responds to but does not address the causes of the environmental problems. Some argue that this is only possible by adopting measures that would result in the improvement of environmental conditions-lower population growth, improved employment opportunities, and better education, for example [36]. However, such prescriptions fail to recognise that existing inequalities militate against the achievement of such goals and deflect attention away from the underlying causes that perpetuate unsustainable practices. Studies from Africa show that educational attainment plays an important role in predicting migration, though the role of education has changed over time, being of less importance in the past [41].

The reasons why people embark on migration are complex-to improve their own and their families' economic circumstances and/or to escape environmental or other threats. From work undertaken in Nepal, the underlying causes of migration are not only related to severe environmental degradation - the gradual deterioration of living conditions can be as significant a driver [29]. According to the UK Foresight project on migration and environmental change [30], migration offers opportunities, but to take advantage of them requires access to resources. In cases where deteriorating environmental conditions have degraded household incomes, it reduces the ability of households not only to send migrants to diversify incomes but also limits the ability to adopt adaptation strategies [31]. After natural disasters, middle-income households in poorer regions may experience greater rates of migration than low- and high-income households, as the former cannot afford to migrate, and the later have resources that insulate them [31]. Thus, it is those people and communities that cannot relocate through migration that are at greater risk, becoming in effect trapped populations. On the other hand, the diversification of income through migration and remittances can allow communities and family members to stay and build resilience, though this needs to be supported by other interventions. Research from India and Mexico has shown that the experience of out-migration leads to changes in social values and alters the management of communal resources, with traditional norms becoming less relevant.

The impact of environmental disruption on households depends on the assets (capitals) that the household has access to. In this context, the inclusion of migration as a response can be viewed as a livelihood strategy. Migration extends the coping ability of households, particularly among rural households. However, being in receipt of remittances from family members who have emigrated does not necessarily lead to improvements in agriculture [42], particularly in cases where the institutional, environmental, and market contexts do not provide appropriate support for agricultural development. In some cases where migration results in a shortage of labour inputs, it can result in reduction in areas under cultivation and worsened vulnerability. Following Hurricane Mitch in Honduras, outward migration by young men and the more well-off community members was a common response [37]. The effect was to degrade the communities' human capital, though it would appear that Mitch just brought the decision to a head. Similarly, the combination of economic hardships, environmental degradation, and a lack of policy intervention in Hispaniola left few adaptation options other than migration [43].

Whilst there is an emerging consensus that climate change and climate variability will have negative impacts on environmental and human systems, and that these could bring about the displacement of communities, there is little agreement as to how significant climate change could 
be in respect of migration [31]. One school of thought sees migration and the effects of climate variability within the context of traditional drivers of migration-push-factors including environment and lack of opportunities; pull-factors, the reverse of push-factors; network factors which facilitate or hinder movement; national policies; and personal factors. In this respect, changes in environmental conditions are a driver affecting factors such as living conditions and economic well-being. The UK Foresight report provides an illustration of how environmental drivers can lead to migration [44]. Some have argued though that undue weight has been given to environmental factors and that there is as yet little good evidence [45], implying that climate-induced migration may not be as significant as some writers suggest. Local context would serve to modulate the degree to which environmental factors are of importance. Accordingly, environmental factors are not seen as the main contributor to migration [37,38]; other factors, such as the state of infrastructure adapted to withstand extreme events, reduces the migration susceptibility of households. However, reported studies have shown that they do influence migration across international borders [37] but that the effects differ from one country to another. Social capital in the form of support networks is another mitigating factor [31]. It is difficult to isolate the relative importance of contributing factors, reflecting the complex interaction between natural environmental and human systems [32]. Certainly, community, household, and individual contexts are important migration factors shaping if it occurs and the destination [37]. Those who are left behind are often the women, children, and the elderly, and even though they may benefit from remittances to households, they are still faced with having to deal with the day-to-day consequences of environmental degradation.

Through work such as the IPCC Special Report [7], there is a track record of highlighting the impacts of climate change through reference to SIDS, emphasising their vulnerability to climate change. In this, SIDS themselves have also used climate change to highlight their vulnerabilities within the international community. The adverse impacts of climate-related environmental phenomena impacting on society are termed disasters-the intersection of hazard and vulnerability resulting in damage and disruption, the implication being that, without vulnerability, there would not be disaster, with vulnerability being a combination of socio-economic factors, external factors, and societies' abilities to deal with environmental phenomena [46]. This has given rise to a narrative in which SIDS were formerly resilient but now, due to climate change, are vulnerable, which is an over-simplification, as island populations have historically dealt with the vagaries of climate, societal, and environmental conditions. Population mobility has been one of the coping strategies [47]. Societal change through population movement and mobility is seen as contributing to resilience, and climate change will not alter this but rather add another factor into the reasons and drivers of migration [46]; it will have a multiplier effect.

The complexity of the relationship between climate change, environment, and migration means that no single narrative can explain all environmental influences on migration. Climate variability and how it manifests through environmental changes in characteristics such as land suitability and the range of responses of socio-economic systems need to be examined within specific contexts. One view is that much of migration ascribed to environmental factors is really a traditional form of coping and, as such, is part of an adaptation response and not a response to environmental change [48].

\section{Migration Patterns}

The abolition of slavery in 1833 and full implementation by 1838 provided the conditions which allowed former slaves to migrate out for part-time jobs. Population counts from the 1840s show a disproportionately high number of females, indicating out-migration of males for wage labour. Men from Carriacou left, often for several seasons, as part of an intra-Caribbean shift of labour to sugar plantations in Trinidad and Guiana and to Venezuelan cacao plantations that went on through the latter half of the 19th century $[49,50]$. Migration was a response to the limited economic opportunities in Carriacou, low wages, and several years of droughts, compounded by ecological change brought 
about by the cultivation of steep hillsides susceptible to excessive run-off and soil erosion and soil compaction from introduced livestock.

Patterns of migration destinations have shifted throughout the 20th century, mirroring the availability of job opportunities. In the first decade, construction of the Panama Canal drew workers from across the Caribbean, including Carriacou. During the 1920s and 1930s, migration shifted the sugar estates of Cuba and mining, farming, and cities in the Eastern USA. Then, the development of an oil industry in Venezuela, Aruba, and Curacao in the 1940s drew migrants there. After the Second World War, there were jobs in factories and in construction in England. Most of the jobs on offer required relatively unskilled labour. Most of those taking up the opportunities left for between two and three years before returning and would have been to more than one destination. Many who left never returned. The goal of those who did was to earn enough to build a house and be economically secure. From interviews with female-headed households in 1973, females travelled less often; of the 70 interviewed, 23 had only gone as far as Grenada, and eight had never left. Of the rest, most had only gone as far as Trinidad, and in almost every case, the travel was not related to employment [49]. Since 1921, the annual rate of emigration has been calculated at around 20 per 1000 per year, increasing to over 30 per 1000 after 1960 [11].

The gradual introduction of requirements and restrictions on travel and immigration to destination countries starting from 1924 in the USA through to the United Kingdom in 1962 had a profound effect on migration, not just from Carriacou [50]. The form filling, qualification requirements, visas, health certificates, and increasing costs associated with leaving had several effects. After going through such requirements, the successful ones have tended not to return. Formal immigration requirements have favoured the better off, i.e., better able to pay for supporting documentation and better educated emigrants, as well as those who already have family connections in the destination country. Destination countries with particular skills shortages often incentivised immigration. Although the numbers meeting specific immigration requirements declined, dependents were able to join those who had already emigrated.

Within the Caribbean, particularly since the wave of independence starting in the late 1960s, the free movement of peoples has been increasingly circumscribed. The free movement of Caribbean Community nationals has the goal of eliminating the need for work permits and permit to stay visas, but it has its restrictions and limitations to certain categories of workers. The supply of unskilled labour has been increasingly met through illegal immigration.

A 1984 study [21] concluded that every family in Carriacou owned livestock, cultivated, and had at least one family relative living abroad. Two thirds of all farmers reported that they did it part-time, and due to the effect of male migration, $59 \%$ of farmers were female. Remittances were considered an integral part of household income. It also noted that, in addition to remittances, savings and pensions from returnees who had lived and worked abroad were another source of income. Off-farm income opportunities were limited, and to a large extent still are, to fishing, occasional employment of government projects, some retail employment, government employment, and tourism-related activities.

Improvements in education, especially secondary education, along with the development of the University of the West Indies, particularly the Barbados Campus opening in 1963 to serve the Eastern Caribbean, increased the opportunities of obtaining university degrees. The percentage of the Grenadian population attending secondary school or higher was 32.5\% according to the 2011 census, and the percentage of those with an associate degree or higher were $8 \%$ and $10 \%$, respectively, for Carriacou and Grenada as a whole. Between 2001 and 2011, the percentage of the population of Carriacou with no formal qualifications dropped from $78 \%$ to $47 \%$, similar to the general population and indicating an increasingly better educated society. The top destination countries for emigrants are the United States, Canada, and the United Kingdom, all of which have over the years tightened their immigration policies, restricting it to those with particular skill sets required by the countries, e.g., teachers, nurses, and healthcare professionals. The result is that those emigrating are the better qualified, which contributes to a brain drain from the country $[9,51,52]$. 
Estimates of the numbers of people emigrating are difficult to ascertain, but it has been estimated that Grenada has a $2 \%$ annual emigration rate and is among the top five developing countries in terms of the share of college-educated citizens leaving [3]. The number of Grenadians living outside of the country is approximately 230,000 . In the case of Carriacou, the average number of emigrants per year has been between 150-200 persons since the end of the Second World War [11]; in other words, since then, the island has lost more people to emigration than its current population. Up until the 1950s, more men were leaving than women, but since the 1950s, the balance between men and women has evened out. The pattern of migration, which has shifted from the supply of unskilled labour to the emigration and growing diaspora of better educated people continues to support the island's population and underpin its economy.

\section{Impact of Changes in Environmental Conditions on Carriacou}

It has only been in the last few decades that attention has been given to characterising drought severity, even less attention has been given to the systematic collection of data on the economic impact, and hardly any has been given to documenting social impacts, other than at a broad-ranging scale. Much more attention is paid to the estimation of the economic impacts of fast-onset hydro-meteorological events such as hurricanes. It is thus almost impossible, given the vagaries of data collection, to draw direct linkages between the occurrence and severity of a particular drought event and impacts on livelihoods and by extension migration. Evidence from the literature suggests that such linkages do exist, but they are complex and work at multiple levels. There is a suggestion from historical records that prolonged dry periods during the mid-1800s was responsible for outward cyclical migration from Carriacou [11], also a period of deteriorating economic conditions.

A comparison of land use data from 2001 and 2012 indicates that, whereas approximately $34 \%$ of the land area was under some form of agricultural practice, cultivated, or pasture in 2001, this had decreased to $27 \%$ by 2012 . A contributory factor has been the continued process of land degradation and erosion that has made it increasingly difficult to maintain agricultural production, with concomitant impacts on household incomes and living conditions. Land degradation, caused primarily through inappropriate land use practices-clearance of primary forest and growth of secondary forest, cultivation on steep slopes, soil compaction by livestock, the impact of bush fires, increased run-off and soil erosion - and land tenure patterns have been cited for decades as adversely affecting agricultural productivity. The impact of drought, in the absence of mitigation and adaptation measures, magnifies the long-term adverse impacts of environmental deterioration not just on the island's ecosystem but also on households who depend in part on agriculture for their livelihoods.

From 1950, Grenada, and by extension Carriacou, has experienced over 12 severe drought episodes [53,54], including 1951-1952, 1957-1964, 1971-1973, 1986-1996, 1998, 2009-2010, and 2014-2017. Apart from the prolonged droughts in the 1800s, the significant droughts in the mid-1930s to mid-1940s, mid-1960s to mid-1970s, and recently in 2000-2001 coincided with population dips after the drought events (see Figure 5). These population dips are mainly attributable to out-migration. For example, after the droughts in the 1980s, there was a population recovery or growth up to 2001, when another severe drought occurred, and population dip was observed thereafter. The most recent drought was the most severe within the recorded time period. The drought period in the 1980s resulted in losses of up to $40 \%$ of all livestock on Carriacou [55], and similarly in 2009-2010,

"I lost the most, eighteen heads of cattle and forty-something heads of small ruminants, from the lack of food and water". Carriacou farmer, 2012

In addition, farmers experienced crop losses either through not having enough water or not being able to afford to buy water to wet crops. Figures for recorded loss of agricultural production in the Grenadines ranged from a minimum of $20 \%$ upward, depending on the crop [56]. Other associated problems included 
"During that period I had problems with rats, manicou and other creatures getting into the water systems because they were suffering from water problems. I actually lost quite a bit of water during that period to animals getting into the tanks even though they were properly sealed rats and other creatures found a way to get in". Carriacou hotel operator, 2012

A farmer described the present situation and the challenges he faces:

"The last 5-6 years the pattern changed, its more variable. There used to be crops in June before but not anymore. Rain is not sufficient, the wells brackish and water going down. The ponds drying up quicker so little water for cattle from ponds. The productivity of the crops is going down due to variability of the weather, the crops are small and perish in the heat. I used to export to Trinidad, sheep and goats but not much now. Now more difficult to make a living". Farmer, 2019

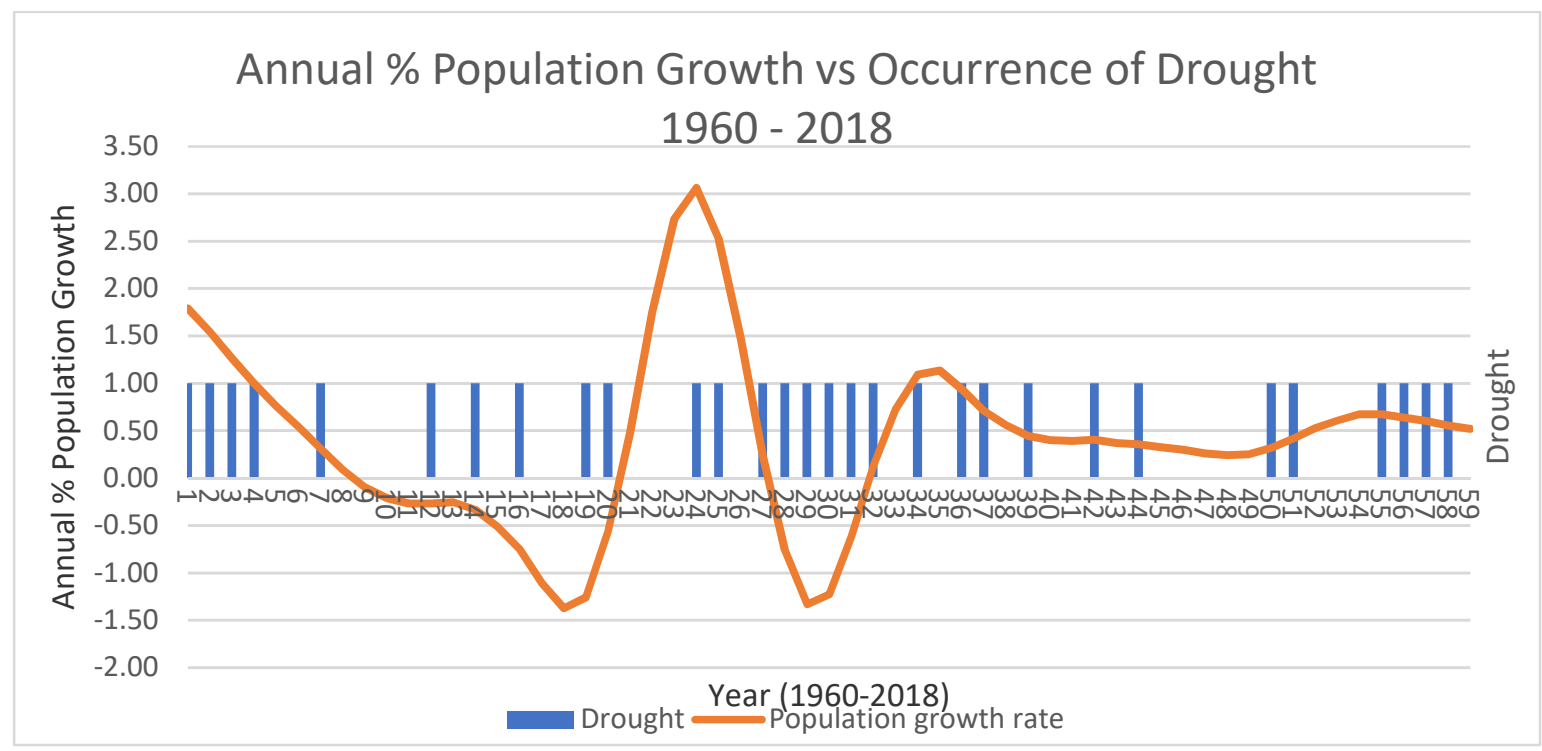

Figure 5. Annual population growth vs. occurrence of drought conditions, 1960-2018 (1 = 1960 on $\mathrm{x}$-axis).

The tourism sector also suffered: due to the low rainfall, there was insufficient water in the storage tanks, forcing hotels to try to purchase water when they could not access additional supplies from other sources. At one point, $340 \mathrm{~m}^{3}$ of water had to barged into the island as emergency relief. Other recorded impacts included bush fires, an increase in cases of gastro-enteritis (particularly among children), and a reported increase in crime and rustling. The loss of livestock was a particular cause of hardship, as cattle, sheep, and goats are assets which can readily be sold to generate a cash income for households. Whilst Carriacou has always been a net importer of fresh produce, the loss of local production had a mutually reinforcing twofold effect on households. First, a loss of production meant a greater reliance on purchased foodstuffs; second, decreased production increased prices of goods, putting a strain on household resources and reducing the amount and quality of foodstuffs.

Whilst it might be tempting to link the downward population trend with the impact of droughts, there has been no research to link the two. The marked decrease in population, through migration, in 1981 is associated with political and economic conditions in the country in the late 1970s, indicating that economic conditions are likely to be a primary factor. This is in line with what has been reported in the literature [28,39]. Furthermore, the influence of colonial conditions of production continue to affect social structure, land use, and economic opportunities, necessitating cyclical migration in order to sustain household livelihoods through the diversification of sources of income. 
The diversification of household incomes is a strategy for increasing household economic resilience, and migration and the sending back of remittances is an established part of that strategy. As already noted, every household on Carriacou has at least one family member who has migrated. It is notable that the majority of migrants have not migrated to mainland Grenada (there are 37 common family names among the population; although some of these names occur in Grenada itself, the numbers are relatively small) but rather to other countries, increasingly beyond the Caribbean. Apart from remittances, most families have diversified their sources of income and do not rely on agriculture for their main source of income. Income-generating opportunities include fishing, retail, and tourism, some of which tend to be seasonal in nature; for example, employment in construction tends to occur during the dry season. In Grenada, the government is the biggest employer, accounting for $15 \%$ of the working population. While there are no available figures, using these ratios implies that there are some 450 people employed by the government in various capacities-on average, one household in four has someone who works for the government. It may be inferred that, with the diversification of income sources and a lesser reliance on climate sensitive activities such as farming, households are at present relatively insensitive to climate extremes such as drought.

This, however, may not be the case, for reasons already touched on. It has been shown that droughts impact households through multiple pathways-increasing living costs, reducing income generating opportunities, and diverting savings. Households can be vulnerable in other ways. One of the factors that has been cited as contributing to resilience in the face of environmental and economic stressors is social capital in the form of networks. Research carried out in 2015 by the University of the West Indies into livelihoods vulnerability using a 'capitals' approach found that the social capital component was the most vulnerable component with the groups, and the networks sub-component contributed the most to the medium-high vulnerability assessment. This was taken as a reflection of the family-centred nature of social relationships on the island. Within the human capital component, climate knowledge and adaptation also indicated medium to high vulnerability.

The changing nature of outward migration from Carriacou potentially poses a challenge. For some, the lack of what would be seen as meaningful employment opportunities coupled with high rates of youth unemployment and the perception of agriculture as being 'hard' and tainted with slavery are a significant counter-weight to reasons for not considering migration. The community is losing those with intellectual capital and skills potential to countries where there are established diaspora, where there are employment prospects, and where the quality of life is perceived to be better. The observation from other migration research is that it is those who are the more vulnerable and have less 'capitals' to draw on that get left behind and who would find it increasingly difficult to adapt to a changing set of climate and environmental circumstances. Whilst there is no hard evidence so far that the changing climatic conditions have increased levels of migration, this may not hold into the future.

\section{A Fight or Flight Future?}

The future prospects for Carriacou and its people depend on a number of inter-related factors-changing socio-economic conditions, the impact of climate change and variability, environmental responses to climatic and anthropogenic changes, political decisions around the level of intervention and development of Carriacou, and regional economic growth and development. All of these elements are open to varying degrees of speculation.

Under the Sustainable Water Management under Climate Change in Small Island Developing States of the Caribbean research project carried out by the University of the West Indies-CERMES, the impact of climate change and variability on water availability was investigated. From the results of the hydrological modelling [57], all models show an increasingly negative water balance for Carriacou, driven by declines in rainfall and increases in potential evaporation due to temperature increases. As a result, total water yield decreases by up to $53 \%$, depending on the climate scenario. The annual shallow aquifer recharge decreases by between $13 \%$ and $45 \%$. For all scenarios, water yield decreases are particularly pronounced in September to November, with daily mean water yield decreasing by 
between $58 \%$ and $72 \%$. Extreme flow events may be short-duration and spatially small in extent, resulting in increased erosion. Periods of drought become more frequent and extreme.

The Water Evaluation And Planning (WEAP) system, software developed by the USA Centre of the Stockholm Environment Institute) was used to investigate the extent to which demand for water across might be met by 2050 [58], using different climate and socio-economic scenarios. The results indicate that in the absence of additional water sources such as desalination, demand for water would only be met for a maximum of four months (July-October), with unmet demand being greatest in the month of December. The presence of a desalination plant on Carriacou does provide an additional source of supply, but it is comparatively expensive, and whilst this would be used to satisfy domestic and other commercial demands, uptake for agricultural or livestock purposes is likely to be severely constrained. The potential impact of an increasingly drier climate with higher ambient temperatures on the ecosystem have not been investigated. Using work on potential vegetation changes in the Nariva Swamp area of Trinidad as a proxy, forest composition is likely to change, with an increase of dry tolerant tree and shrub species, as well as an increase in the total area of secondary forest as more land is abandoned.

As a result of the changing climate conditions, planting times are already changing. Traditionally, farmers began planting field crops at the beginning of June in anticipation of rains; now, planting is being delayed until the end of June or start of July. Thus, the growing season is already contracting. There are at present only four commercial farmers (all the rest farm on a subsistence basis). Previously, the number of commercial farmers was higher, as was the area of land under cultivation. Difficulties are already being experienced in securing fodder for livestock, particularly during the dry season, according to the Carriacou Farmers Association. This could be suggestive of a contraction of overall agricultural production and possibly a shift in balance with livestock, though lower in numbers, contributing more to overall production. Lower stock levels will adversely affect household incomes and general food security. It will be increasingly challenging, with the current modes of production, for agriculture to continue to be a viable component of the local economy, even at a subsistence level. Fishers too have already been affected by increases in sea surface temperatures; in response to higher near shore water temperatures, fish stocks have moved away into deeper waters. Irrespective of what effect this might have on fish stocks, this migration means that fishers now have to expend greater effort and incur increased costs just to maintain current levels of production.

Overall, dependence on the importation of food and other goods will probably increase substantially, with a concomitant significant decrease in local productive capacity. Scarcity usually results in higher costs, which disproportionately affect the poorer members of the community. Imported goods are likely to be costlier not just because of the costs associated with importation but through the climate-related impacts discussed affecting the sources of production. Some sectors will be better able to adjust as they will be able to pass on the additional costs (sectors such as hotels, tourism services, and as those servicing yacht-related tourism). Even here, however, the price elasticity of tourism may become a limiting factor. The costs associated with the provision of water are likely to increase, and this too will influence decisions regarding what and how much can be used and the prioritisation of the most necessary of uses. It will also result in a greater reliance on a single source of water production, desalination, a sophisticated technological solution that requires a sound operation and maintenance regime. The cumulative effect is likely to be a severe contraction of agricultural activity and water and food insecurity.

There may be some relief in terms of remittances, in that these may increase in value and not just in importance to family household incomes. The bigger question is the extent to which other income-generating activities could serve to offset increases in the cost of living. It is a question that is related to the ability of government to provide services and stimulate and facilitate economic growth and development through policies and programme interventions. These abilities are dependent on the availability of resources, determined by several factors, some of which it has a high degree of control, and others over which it has little control. Grenada's economy, like that of most the 
Caribbean, is open and dependent on the performance of the global economy [59]. It has already been noted that the level of investment in climate change adaptation is low and that there is limited fiscal space to increase investment and a high degree of dependence on external funding for the development and implementation of adaptation measures. Government budgetary commitments to maintain basic service provision and the servicing of debt continue to claim the major share of revenues. Should regional and domestic economic conditions stagnate, this would have severe implications for Carriacou, and the opposite is also the case-improving economic conditions would allow greater investment in the development of Carriacou. The relationship between future regional socio-economic development pathways and climate change have been explored through the development of future foresight scenarios [60]. The work illustrates how economic opportunities at the country level might be shaped by regional and global factors.

It has been hypothesised that a shift from linear to non-linear migration may occur when a resilience/vulnerability tipping point is reached and a community can no longer continue to function in the way it had; it has to adapt to a new set of emergent conditions. Such a tipping point might be the result of one or more factors-the occurrence or repeated occurrence of particularly severe hazards or intensification of hazards that simply overwhelms a population's ability to recover such as a large-scale collapse of productivity and results in increased chronic vulnerability and collapse of livelihoods. This may be due to lack of effective planning or interventions (policy or programmes) or increased vulnerability due to policy or economic trends combined with an intensification of hazard so as to make life for some or all members of a community untenable. It has been theorised that climate change may precipitate non-linear migration associated with the mechanisms outlined as a result of increases in the severity and/or frequency of climate-related hazards such as droughts, even where vulnerability is not exacerbated by non-climatic factors. Where endogenous policies, exogenous economic trends, or climate change via its impacts on resources act to increase vulnerability, non-linear migration might result $[41,61]$. Non-linear migration occurs when stresses reach a threshold or "tipping point" beyond which people are unable to cope, leading to a step change in the nature of migration such as increasing numbers migrating. Vulnerability is unlikely to remain static, and changes in the nature and/or behaviour of hazards combined with changing patterns of vulnerability are likely to account for a significant proportion of non-linear migration [41].

An inability to invest and support development opportunities in Carriacou will constrain economic opportunities for the population. Under certain conditions envisaged in the foresight scenarios, it could be envisaged that there would be a marked deterioration in the provision of government services, resulting in an increasing impoverishment of large sections of the population and a contraction of the island's economy. Under these conditions, it is possible that the patterns of migration would have to change; some may be able to relocate to the mainland, whilst the outward migration of those with greater intellectual or financial capitals would continue to leave. Under these conditions, drought conditions would have a more pernicious impact on prevailing conditions. Conversely, under the more optimistic scenarios, it is likely that investments would be made which would provide additional and alternative opportunities that could offset some of the impacts associated with climate change and environmental hazards on economic development. Under these circumstances, the underlying drivers of migration would not change significantly. This presumes that the developments are such that they would include adaptations to climate change, increasing the resilience of the social, economic, and environmental fabric of the island, thus lessening the potential impact of extreme environmental hazards.

The historical migration trends of Carriacou can be characterised as being of two distinct types-cyclical and permanent migration of persons with basic skills sets in response to a lack of economic employment opportunities in which environmental conditions have had an influence primarily through affecting agricultural productivity; and beginning in the latter half of the 20th century, permanent outward migration in response to a lack of employment opportunities aligned with better opportunities in countries like Canada and the USA but contingent on the persons having particular skill sets or levels of education (this later being less influenced by environmental conditions 
and the impact of extreme hazards). Since 1995, the crude net migration rate for the country as a whole has been around -8 per 1000 population, and this is expected to continue through to the 2050s, whilst the natural rate of population increase is due to decline. Therefore, an increasing percentage of the population is expected to migrate. Of those migrating, nearly $80 \%$ are destined for North America. They are predominantly in their 20s and 30s, have higher educational attainment and income levels, and are more likely to settle permanently in their host country. This is mirrored in the steady increase in remittances back to Grenada. Anecdotal evidence from persons in Carriacou suggests that, if anything, these outward migration trends are more pronounced on the island. Many young, working-aged persons have been leaving, evidenced in part by declines in school enrolment. The role of climate change as a contributing factor to migration is secondary-again, anecdotal evidence does not suggest that it is at the moment a primary driver but rather a contributory factor working through impacts on livelihoods. Looking to the future, the potential pace of migration from Carriacou is likely to continue to be influenced by economic conditions and development opportunities underlain by environmental stresses. That said, it is also evident that future economic conditions and development opportunities are going to be shaped by climate change and variability and the associated magnification of extreme environmental hazards and their impacts.

\section{Conclusions}

Carriacou has a long history of outward migration, responding to the prospect of better external socio-economic conditions as compared with the limited livelihood opportunities available on the island. The nature of migration has changed over the last 50 years. In the past, it was predominately cyclical, responding to employment opportunities and, after a period of time, returning to and investing in the island. Since the 1980s, migration has been of a more permanent nature, particularly amongst those with higher levels of education and skills. That said, the underlying drivers of migration have not changed in nature. The opportunities for development and income generation on the island are limited, whilst migration opened up better prospects for financial advancement and diversification of household incomes, thus underpinning the local economy. Over the last 200 years, Carriacou has transitioned from a plantation/commercial to a small holding/subsistence-based local economy, and more recently, to a mixed economy including tourism and government employment. Whilst its economic importance may have declined, agriculture is intimately involved in the fabric of the island's society and way of life. The inability of the agricultural sector to underpin the local economy is a result of inappropriate land management practices, together with unsupportive environmental conditions, which have resulted in the decline of productivity, income generation, and household food security. Such a situation has acted as a negative feedback to which migration and income diversification has been a response. Historically, periods of environmental stress such as droughts have influenced migration patterns, which themselves have also had a negative feedback, with remittances substituting local incomes and at the same time removing economically active persons from the workforce. It might be argued that this has affected the potential for agricultural production and livelihoods or employment opportunities.

Water availability is the overarching factor constraining development and has had a defining influence on the economic and social life of Carriacou. It has shaped the agricultural practices and possibilities that were for so long the mainstay of the local economy, and it has influenced social networks and resource sharing. Climate variability and climate change are already negatively affecting water availability and having knock-on effects across the local economy. The projections, even under a best-case scenario, are likely to result in further water stress, unless adaptation and mitigation measures are put in place. Climate variability has already increased environmental stress and had a negative impact on agricultural productivity, particularly impacting livestock. Declining agricultural production and productivity, increases in the cost of living, and limited local alternatives are likely to negatively affect the local economy and society. At the same time, inadequate water supply could adversely affect the emerging tourism sector. Whilst the linkages between climate change and migration are still to be resolved, it seems likely that projected increases in the frequency, intensity, and duration of 
droughts would increase environmental stresses, severely affecting water supply and agriculture and, consequently, social welfare. This, in turn, would play a role in individual and household decisions around migration.

The key adaptation measure has to address the issue of water scarcity, as water availability is such a cross-cutting factor that it affects economic viability and social well-being. Support for income-generating opportunities will rely on having a more assured source of water supply. Solar-powered desalination, although as yet not widely accepted, is already making domestic supply, tourism, and commerce more resilient, particularly to drought conditions. This should be complemented by other sources of income generation, and it is here that agricultural development could play a role, especially given that it previously underpinned the local economy. Water yields can be increased through land use management and more extensive water capture and retention, which would build on the existing culture and indigenous knowledge of rainwater harvesting. The adoption of climate smart agricultural practices, including drip irrigation, would make a significant difference to productivity and allow extension to include new crops. Other structural factors would also have to be addressed, such as the barriers existing land tenure arrangements pose, improved access to support services, and improvements to transportation to reduce time and cost to market. Such measures are unlikely to halt outward migration, nor do they have to try to. The creation of economic opportunities would benefit those who would otherwise be the most disadvantaged and least able to cope with a cycle of deterioration of living conditions that the increased environmental stresses associated with climate change would bring.

The situation outlined is not unique to Carriacou; many other islands find themselves in similar situations. The provision of investments and climate adaptation initiatives, offering alternative development opportunities would counter this and be a major determinant of the magnitude of the impacts of projected climate change on migration. This is important as, even if those with employment decide to remain, the impacts of projected climate change on the quantity and cost of water and food supply could undermine a dignified life and contribute to the decision to migrate. However, the ability to implement mitigatory actions depends to a great extent on the health and vitality of the national government and economy. This too would be affected by the intersection of macro-economic forces, climate change, and the global responses. An inability on the part of the central government to provide for the future development could well result in non-linear migration with the relatively better off choosing to migrate to third countries and those with fewer assets gradually abandoning the periphery (islands such as Carriacou) and relocating nationally.

Author Contributions: Conceptualization, A.C. Formal analysis, A.C. Investigation, A.C. Writing-original draft preparation, A.C. and D.Y. Writing-review and editing, A.C. and D.Y.

Funding: This research was partially funded by the International Research Development Centre (IDRC) of Canada, grant number 107096-001.

Acknowledgments: We acknowledge the generous support of the people of Carriacou and the Ministry of Carriacou and Petit Martinique without whose participation this work would not have been possible.

Conflicts of Interest: The authors declare no conflict of interest.

\section{References}

1. UN. Small Island Developing States. United Nations, 2019. Available online: https://sustainabledevelopment. un.org/topics/sids (accessed on 25 September 2019).

2. Bruckner, M. Effectively addressing the vulnerabilities and development needs of small island developing States. In Background Papers, Department of Economic \& Social Affairs, United Nations; RePEc; UNDESA: New York, NY, USA, 2013; p. 37.

3. OECD. Making Development co-Operation Work for Small Island Developing States; OECD: Paris, France, 2018. 
4. Josling, T.; De Salvo, C.P.; Shik, O.; Boyce, R.; Foster, W.; Derlagen, C.; Muñoz, G.; Santos, J.D.L.; Nuenninghoff, S.; Bayard, B.; et al. Agricultural Policies in the Caribbean: A Regional Analysis. In Agricultural Policies in the Caribbean: A Regional Analysis; Felipe Herrera Library (Inter-American Development Bank): New York, NY, USA, 2018.

5. Nurse, L.; Mclean, R.; Agard, J.; Briguglio, L.; Duvat-Magnan, V.; Pelesikoti, N.; Tomkins, E.; Webb, A. Small Islands. In Climate Change 2014: Impacts, Adaptation, and Vulnerabilities. Part B: Regional Aspects. Contribution of Working Group II to the Fifth Assessment Report of the Intergovernmental Panel on Climate Change; Barros, V., Field, C.B., Dokken, D.J., Mastrandrea, M.D., Mach, K.J., Bilir, T.E., Chatterjee, M., Ebi, K.L., Estrada, Y.O., Genova, R.C., et al., Eds.; Cambridge University Press: Cambridge, UK, 2014; pp. 1613-1654.

6. Stennett-Brown, R.K.; Stephenson, T.S.; Taylor, M.A. Caribbean climate change vulnerability: Lessons from an aggregate index approach. PLoS ONE 2019, 14, e0219250. [CrossRef] [PubMed]

7. IPCC. Global Warming of $1.5^{\circ} \mathrm{C}$; An IPCC Special Report on the Impacts of Global Warming of $1.5^{\circ} \mathrm{C}$ above pre-Industrial Levels and Efforts to Eradicate Poverty; IPCC, World Meteorological Organization: Geneva, Switzerland, 2018.

8. Thomas, A.; Benjamin, L. Policies and mechanisms to address climate-induced migration and displacement in Pacific and Caribbean small island developing states. Int. J. Clim. Chang. Strat. Manag. 2018, 10, 86-104. [CrossRef]

9. IOM. Migration in the Caribbean: Current Trends, Opportunities and Challenges; International Office of Migration-Regional Office for Central America, North America and the Caribbean: San Jose, Costa Rica, 2017.

10. Gheuens, J.; Nagabhatla, N.; Perera, E.D.P. Disaster-Risk, Water Security Challenges and Strategies in Small Island Developing States (SIDS). Water 2019, 11, 637. [CrossRef]

11. Hill, D. The Impact of Migration on the Metropolitan and Folk Society of Carriacou, Grenada; Anthropological Papers of the American Museum of Natural History; AMNH: New York, NY, USA, 1977.

12. CSO. Grenada Population Census Statistics; Government of Grenada: St Georges, Grenada, 2019.

13. UNDESA. Road Map on Building a Green Economy for Sustainable Development in Carriacou and Petite Martinique; United Nations Department of Economic and Social Affairs: New York, NY, USA, 2012.

14. Peters, E. Household Consumption of Rainwater in Carriacou and Petite Martinique; Department of Civil Engineering, University of the West Indies, St. Augustine: Port of Spain, Trinidad, 2015, unpublished.

15. Peters, E. Desalination for Augmenting Domestic Rainwater Harvesting in the Grenadines. Proc. Inst. Civ. Eng. Water Manag. 2019, 172, 195-206. [CrossRef]

16. CDB. Country Economic Review Grenada; Caribbean Development Bank: Bridgetown, Barbados, 2018.

17. IICA. Country Profile Grenada: Climate Change and Agriculture; Inter-American Institute for Cooperation on Climate Change: San José, Costa Rica, 2018.

18. World Bank; CIAT (International Center for Tropical Agriculture, Colombia); CATIE (Tropical Agricultural Research and Higher Education Center, Costa Rica). Climate-Smart Agriculture in Grenada; CSA Country Profiles for Latin America Series; The World Bank Group: Washington, DC, USA, 2017; p. 12.

19. GoG. Grenada National Agricultural Plan; Government of Grenada: St. Georges, Grenada, 2015.

20. FAO. Country Programme Framework for Grenada 2016-2019; Food and Agricultural Organization of the United Nations: Bridgetown, Barbados, 2015.

21. Buckmire, K.; Chase, V.; Hammerton, J.; Rao, M. Carriacou—A Reconnaisance Survey; Caribbean Agriculture Research and Development Institute (CARDI): Bridgetown, Barbados, 1984.

22. Kairi Consultants Ltd. Country Poverty Assessment: Grenada, Carriacou and Petit Martinique; Caribbean Development Bank: Bridgetown, Barbados, 2008.

23. World Bank. Climate Change Knowledge Portal for Development Practitioners and Policy-makers. 2019. Available online: https:/climateknowledgeportal.worldbank.org/country/grenada/climate-data-historical (accessed on 25 September 2019).

24. Peters, E.J. Drought monitoring for rooftop rainwater-harvesting systems. Proc. Inst. Civ. Eng. Water Manag. 2012, 165, 301-312. [CrossRef]

25. Hall, T.C.; Sealy, A.M.; Stephenson, T.S.; Kusunoki, S.; Taylor, M.A.; Chen, A.A.; Kitoh, A. Future climate of the Caribbean from a super-high-resolution atmospheric general circulation model. Theor. Appl. Clim. 2012, 113, 271-287. [CrossRef]

26. Lehner, F.; Coats, S.; Stocker, T.F.; Pendergrass, A.G.; Sanderson, B.M.; Raible, C.C.; Smerdon, J.E. Projected drought risk in $1.5^{\circ} \mathrm{C}$ and $2^{\circ} \mathrm{C}$ warmer climates. Geophys. Res. Lett. 2017, 44, 7419-7428. [CrossRef] 
27. Taylor, M.A.; Clarke, L.A.; Centella, A.; Bezanilla, A.; Stephenson, T.S.; Jones, J.J.; Campbell, J.D.; Vichot, A.; Charlery, J. Future Caribbean Climates in a World of Rising Temperatures: The 1.5 vs 2.0 Dilemma. J. Clim. 2018, 31, 2907-2926. [CrossRef]

28. Gomez, O. Climate Change and Migration: A Review of Literature; IDRC Working Paper; IDRC: Ottawa, ON, Canada, 2013.

29. Adamo, S.B.; Izazola, H. Human migration and the environment. Popul. Environ. 2010, 32, 105-108. [CrossRef]

30. Black, R.; Bennett, S.; Thomas, S.; Beddington, J. Migration as adaptation. Nature 2011, 478, 447-449. [CrossRef]

31. Burrows, K.; Kinney, P.L. Exploring the Climate Change, Migration and Conflict Nexus. Int. J. Environ. Res. Public Health 2016, 13, 443. [CrossRef]

32. Warner, K. Environmental change and migration: Methodological considerations from ground-breaking global survey. Popul. Environ. 2011, 33, 3-27. [CrossRef]

33. Vogt, W. The Road to Survival; William Sloan Associates: New York, NY, USA, 1948.

34. Oliver-Smith, A. Nature, Society, and Population Displacement: Towards an Understanding of Environmental Migration and Social Vulnerability; UNU-EHS: Bonn, Germany, 2009.

35. Beck, U. Risk Society: Towards a New Modernity; Sage Publishing: Newbury Park, CA, UAS, 1992.

36. Hugo, G. Migration, Development and Environment; United Nations Publications: New York, NY, USA, 2008; pp. 1-55.

37. Obokata, R.; Veronis, L.; McLeman, R. Empirical research on international environmental migration: A systematic review. Popul. Environ. 2014, 36, 111-135. [CrossRef] [PubMed]

38. Warner, K.; Hamza, M.; Oliver-Smith, A.; Renaud, F. Climate change, environmental degradation and migration. Nat. Hazards 2010, 55, 689-715. [CrossRef]

39. Gray, C.; Bilsborrow, R. Environmental influences on human migration in rural Ecuador. Demographic 2013, 50, 1217-1241. [CrossRef]

40. Tacoli, C. Crisis or adaptation? Migration and climate change in a context of high mobility. Environ. Urban. 2009, 21, 513-525. [CrossRef]

41. Brooks, N.; Winkels, A. Moving on: Towards a Policy Framework for Addressing Climate Change and Migration; UNDP: New York, NY, USA, 2011; unpublished.

42. Deshingkar, P. Environmental risk, resilience and migration: Implications for natural resource management and agriculture. Environ. Res. Lett. 2012, 7, 015603. [CrossRef]

43. Alsher, S. Environmental degradation and migration on Hispaniola Island. Int. Migr. 2011, 49, e164-e188. [CrossRef]

44. Government Office for Science. Foresight: Migration and Global Environmental Change: Final Project Report; Government Office for Science: London, UK, 2011.

45. Brzoska, M.; Frohlich, C. Climate change, migration and violent conflict: Vulnerabilities, pathways and adaptation strategies. Migr. Dev. 2016, 5, 190-210. [CrossRef]

46. Kelman, I. Islandness within climate change narratives of small island developing states (SIDS). Isl. Stud. J. 2018, 13, 149-166. [CrossRef]

47. King, R. Geography, islands and migration in an era of global Mobility. Isl. Stud. J. 2009, 4, 53-84.

48. Black, R. Environmental Refugees: Myth or Reality? UNHCR Working Papers; UNHCR: Geneva, Switzerland, 2001; pp. 1-19.

49. Richardson, B. The overdevelopment of Carriacou. Geogr. Rev. 1975, 65, 390-399. Available online: https: //climateknowledgeportal.worldbank.org/country/grenada/climate-data-historical (accessed on 6 November 2019). [CrossRef]

50. Pool, G.R. Shifts in Grenadian Migration: An Historical Perspective. Int. Migr. Rev. 1989, 23, $238-266$. [CrossRef] [PubMed]

51. Hope-Thomas, E. Skilled Labour Migration from Developing Countries: Study on the Caribbean Region; Working Paper; International Labour Organisation: Geneva, Switzerland, 2002.

52. Aragon, E.; El-Assar, A. Migration Governance in the Caribbean: Report on the Island States of the Commonwealth Caribbean; International Organization for Migration Regional Office for Central America, North America and the Caribbean: San Jose, Costa Rica, 2018. 
53. Herrera, D.; Ault, T. CSF Caribbean Drought Atlas 2019. Available online: http://climatesmartfarming.org/ tools/caribbean-drought/ (accessed on 19 August 2019).

54. Herrera, D.; Ault, T. Insights from a New High-Resolution Drought Atlas for the Caribbean Spanning 1950-2016. J. Clim. 2017, 30, 7801-7825. [CrossRef]

55. FAO. Drought Characteristics and Management in the Caribbean; Food and Agricultural Organization: Rome, Italy, 2016.

56. Farrell, D.; Trotman, A.; Cox, C. Drought Early Warning Systems and Risk Reduction: A Case Study of the Caribbean Drought of 2009-2010; United Nations Disaster Reduction: Geneva, Switzerland, 2010.

57. Wilson, M.; Galoie, M.; Cashman, A. An Assessment of the Impact of Climate Change on the Future Water Balance of Carriacou Island, Grenada. In Proceedings of the International Climate Change Conference for the Caribbean, Port of Spain, Trinidad \& Tobago, 9-12 October 2017.

58. Drakes, C.; Dasent, C.; Laing, T.; Maharaj, A.; Cashman, A. Exploring A2 Futures: Combining modelling and scenarios to assess water availability and adaptation in the Small Island State of Carriacou. In Proceedings of the 5th International Conference on Sustainable Development, New York, NY, USA, 19 September 2017.

59. Kemp-Benedict, E.; Drakes, C.; Laing, T.J. Export-Led Growth, Global Integration, and the External Balance of Small Island Developing States. Economic 2018, 6, 35. [CrossRef]

60. Drakes, C.; Laing, T.; Kemp-Benedict, E.; Cashman, A. Caribbean Scenarios 2050; Technical Report No.34. CERMES; University of the West Indies: Bridgetown, Barbados, 2016.

61. Bardsley, D.K.; Hugo, G.J. Migration and climate change: Examining thresholds of change to guide effective adaptation decision-making. Popul. Environ. 2010, 32, 238-262. [CrossRef]

(C) 2019 by the authors. Licensee MDPI, Basel, Switzerland. This article is an open access article distributed under the terms and conditions of the Creative Commons Attribution (CC BY) license (http://creativecommons.org/licenses/by/4.0/). 